\title{
Geo- and hydro-acoustic manifestations of shallow gas and gas seeps in the Dnepr paleo- delta, northwestern Black Sea
}

\author{
Lieven Naudts, Jens Greinert, Yuriy Artemov, Marc De Batist
}

\subsection{Background}

Shallow gas has been a topic of major interest to academic and industrial researchers worldwide and this within different scientific fields. Shallow gas occurs in a depth window between $0 \mathrm{~m}$ and $1000 \mathrm{~m}$ below the seafloor. It consists mainly of microbial-formed or thermogenic methane or a combination of both, sometimes with a limited admixture of higher hydrocarbons (propane, butane, etc.). The main interest from the oil and gas industry in shallow gas is because of the possible hazard it poses during drilling, as it can lead to blow-outs and seafloor instability affecting seafloor-based constructions. Besides this, shallow gas can also be an important tool to localize deeper economically valuable hydrocarbon resources and reservoirs. Also in academic research, shallow gas has become a major study object over the last decennia drawing the attention of geologists, geophysicists, microbiologists, geochemists, oceanographers, etc. Shallow gas and seabed fluid flow are global phenomena, which play a fundamental role in various natural processes that affect the geosphere, the biosphere, the hydrosphere and the atmosphere. In order to study the possible effects of shallow gas and seabed fluid flow, it is important to understand the processes and parameters that control its distribution and presence in the subsurface. High-resolution reflection seismics is the main tool that has traditionally been used to determine the presence of free gas in the shallow sediments, and to infer the possible geological controls on its distribution (e.g. impermeable sediment layers) as well as the associated fluid pathways (e.g. faults, permeable sediment layers, diapirs).
In some cases, shallow gas is able to migrate and to reach the seafloor, where gas (free and/or dissolved) might be released into the water column. Since locations of gas release, i.e. gas seeps, at the seafloor often have a distinct morphological expression (e.g. pockmarks, mud volcanoes, ridges); they can easily be detected on high-resolution reflection seismic data, single-beam and multibeam echosounding data and side-scan sonar recordings. In this paper, we present an overview of some of the characteristics and seismic signatures of shallow free gas on different types of high-resolution seismic reflection data. We also discuss the factors that control the distribution of shallow gas and gas seeps in the Dnepr paleo-delta, northwestern Black Sea.

\subsection{Dnepr paleo-delta}

The Dnepr paleo-delta area is located on the continental margin of the northwestern Black Sea, west of the Crimea Peninsula (Fig. 2.1.). Structurally, the Dnepr paleo-delta is situated on the transition zone between the Scythian Platform and the Karkinit Trough in the north, the Shtormavaya Graben, the Kalamit Ridge and the Western Black Sea Basin in the south (Fig. 2.1.). The Western Black Sea Basin formed during the late Cretaceous in a back-arc setting above the northward subducting Tethys Ocean, close to the southern margin of Eurasia. The continental margin west of the Crimea Peninsula consists of Late Paleozoic to Mesozoic basement rocks covered by thick Cenozoic sediments with a thickness of at least $2 \mathrm{~km}$ (Robinson et al., 1996). 


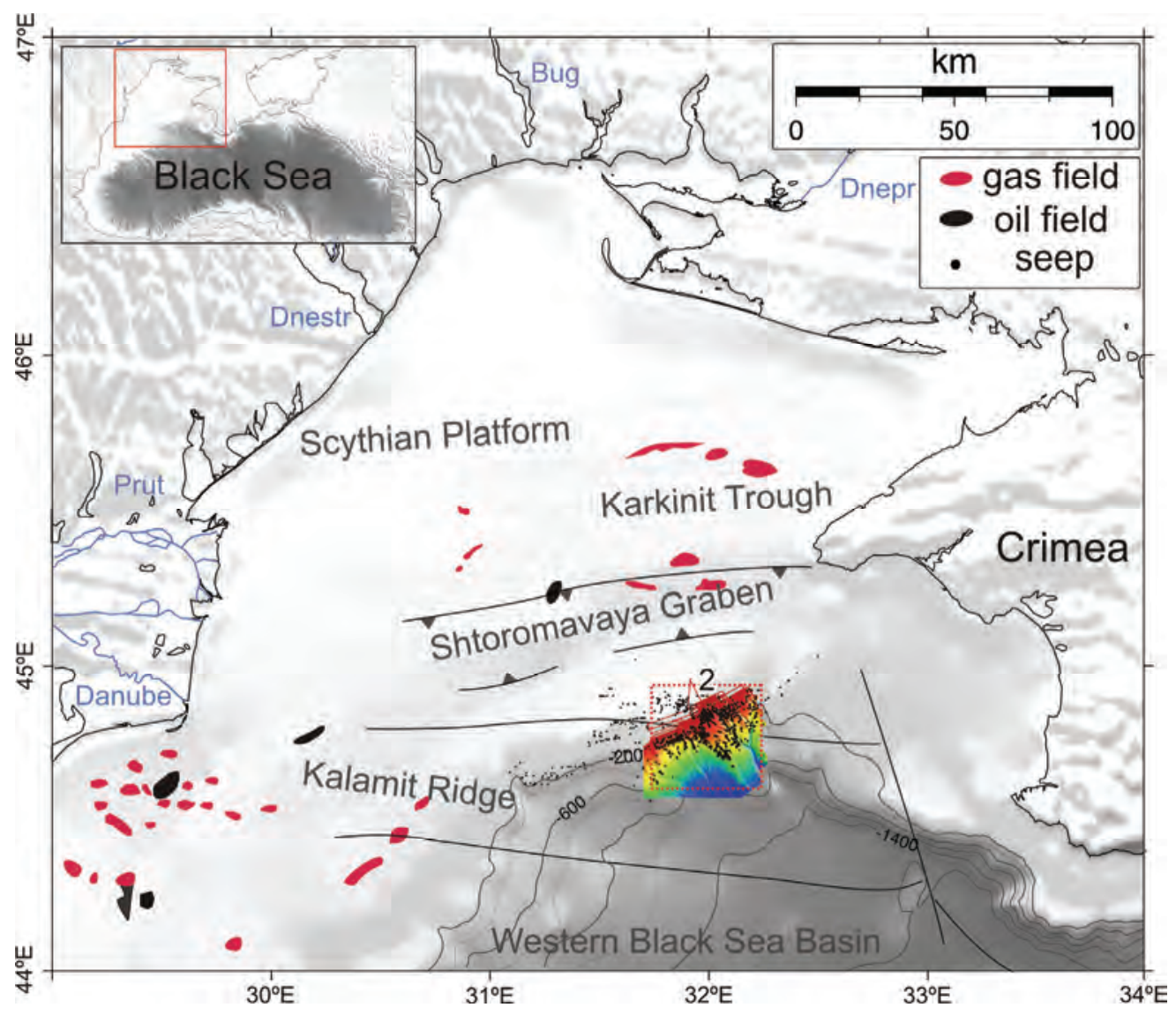

Figure 2.1. Location of Dnepr paleo-delta in the northwestern Black Sea with indication of major structures, deep faults, oil and gas fields and seep locations.

Nowadays the northwestern Black Sea is dominated by a rather wide shelf $(60-200 \mathrm{~km})$ with a shelf break at 120 to $170 \mathrm{~m}$ water depth and canyon systems with large deep-sea fan complexes which mainly developed during sealevel lowstands. During several successive lowstands the main inflowing rivers, Dnepr and Danube, deposited organic-rich material hundreds of kilometers beyond their present mouths forming shelf-edge deltas at the present-day shelf break. The Dnepr paleo-delta is one of these shelf-edge deltas, in which microbial degradation of the organic-rich sediments has led to the formation of shallow gas associated with prolific gas seepage at the seabed. The presence of the shallow gas and gas seeps in the Dnepr paleo-delta already received a lot of attention from different Europeanfunded research projects. The data shown here were acquired during the EU-funded CRIMEA project (2003-2006).

\subsection{High-resolution reflection seismic data}

Three different types of seismic reflection data were acquired using three different sources (5 $\mathrm{kHz}$ pinger, SIG-sparker and GI-gun) (Fig. 2.2.A), each within a different frequency range to extract the best possible information about the underlying geology and shallow gas distribution. The very shallow subsurface was investigated using a deeptow $5 \mathrm{kHz}$ pinger, which was mounted in a towfish together with a side-scan sonar (SONIC-3). The towfish was towed at 50$200 \mathrm{~m}$ above the seafloor. The theoretical resolution (i.e. Rayleigh criterion) is $30 \mathrm{~cm}$, for a maximum penetration of $35 \mathrm{~ms}$. In total $590 \mathrm{~km}$ of $5 \mathrm{kHz}$ data were recorded. To achieve deeper penetration, single-channel reflection seismic data were collected with a SIG sparker source (central frequency of $500-700 \mathrm{~Hz}$ ) and an active 

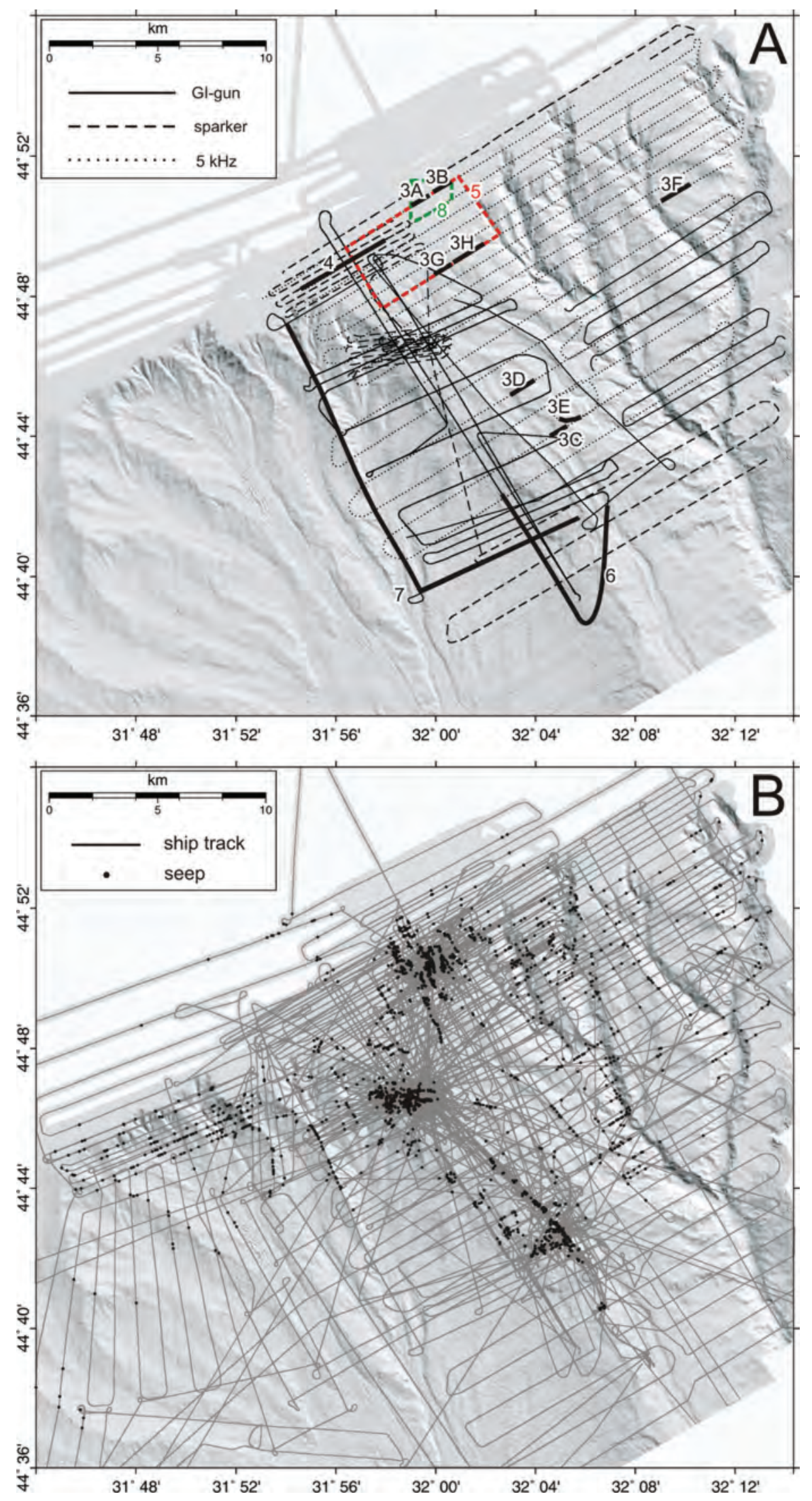

Figure 2.2. A. High-resolution seismic reflection survey lines and outlines for Figs. 2.4.-2.9. (see Fig. 2.1. for location). B. Ship track with hydro-acoustically detected seeps (see Fig. 2.1. for location). 


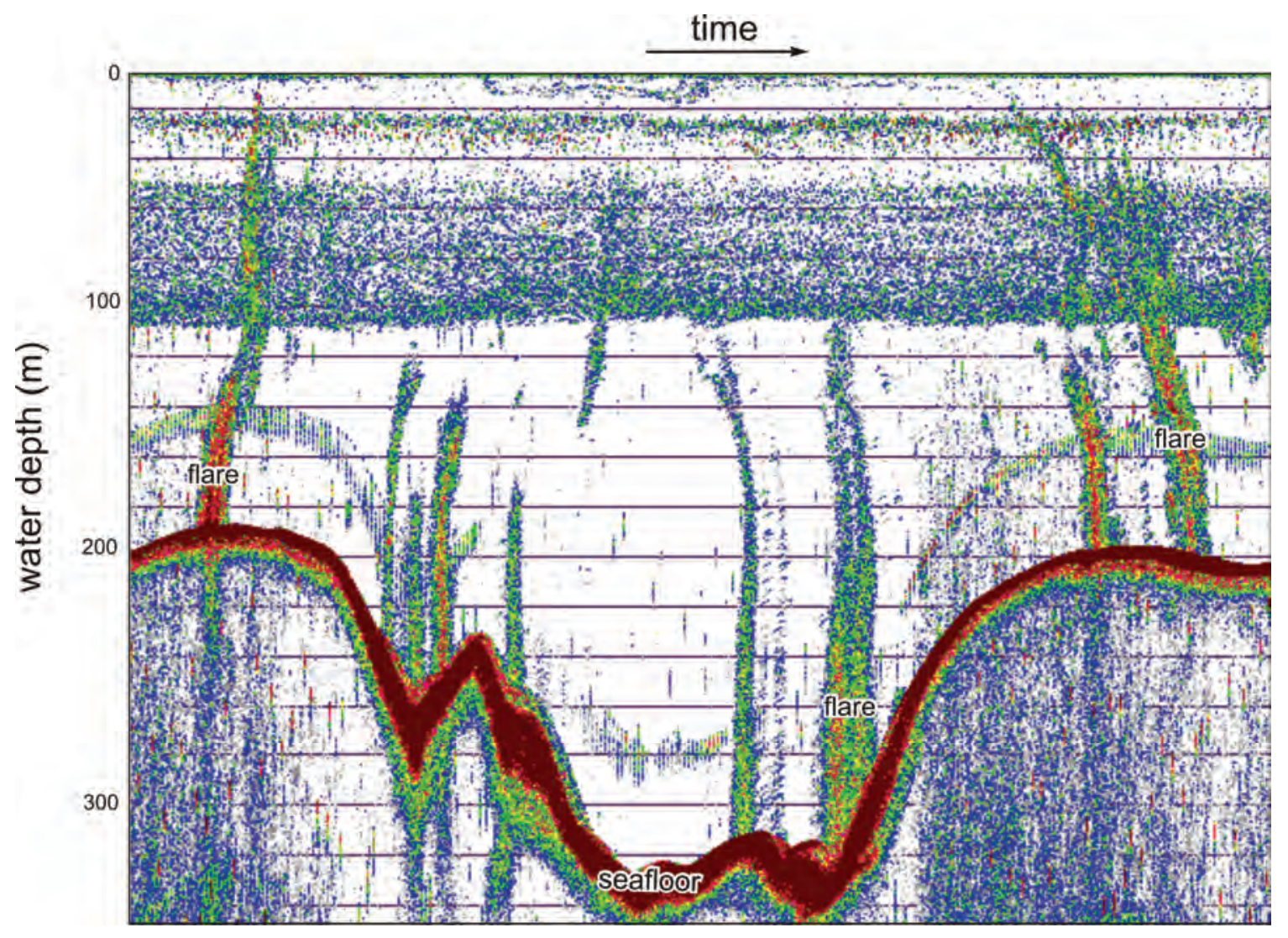

Figure 2.3. Single-beam echogram showing typical hydro-acoustic manifestations of rising methane bubbles (flares) in the Dnepr paleo-delta.

single-channel surface streamer with 10 hydrophones. The theoretical vertical resolution is $1 \mathrm{~m}$ and the maximum penetration is $100 \mathrm{~ms}$. $330 \mathrm{~km}$ of sparker data were recorded. For visualizing possible gas hydrate reservoirs and major depositional units, also multi-channel seismic data were acquired with a Gl-gun source (central frequency of $150 \mathrm{~Hz}$; maximum shooting interval of $8 \mathrm{~s}$ ) and a passive surface streamer with 16 hydrophone groups. The theoretical vertical resolution is $6 \mathrm{~m}$ and the maximum penetration is $600 \mathrm{~ms}$. Multi-channel data were recorded over a total length of $665 \mathrm{~km}$. Data processing involved frequency filtering, velocity analysis, NMO correction, stacking and deconvolution. Interpretation and analysis of the three types of seismic data was carried out with the Kingdom Suite software package. In addition to the acquisition of seismic reflection data, single-beam echosounding was performed for seep detection (i.e. for the detection of gas bubbles released in the water column) using a hull-mounted SIMRAD EK-500 dual-frequency
(38 and $120 \mathrm{kHz}$ ) split-beam echosounder (Figs. $2 \mathrm{~B}$ and 2.3). Seabed features related to gas venting and the presence of shallow gas were additionally imaged by a combination of multibeam echosounding, using a $50 \mathrm{kHz}$ SEABEAM 1050 system, and side-scan sonar imaging, using the $30 \mathrm{kHz}$ SONIC-3 deep-water sonar.

\subsection{Shallow gas}

The presence of shallow gas strongly influences the mechanical and acoustic properties of the sediment (increased sound attenuation, acoustic energy scattering, affecting sound velocity, etc.). Therefore geoacoustic methods, like seismic reflection profiling, are significantly affected by the presence of shallow gas and are therefore very well-suited for the detection of gas in the sediments. Even very small concentrations of gas in the pore space ( $0.5 \%$ gas by volume) 

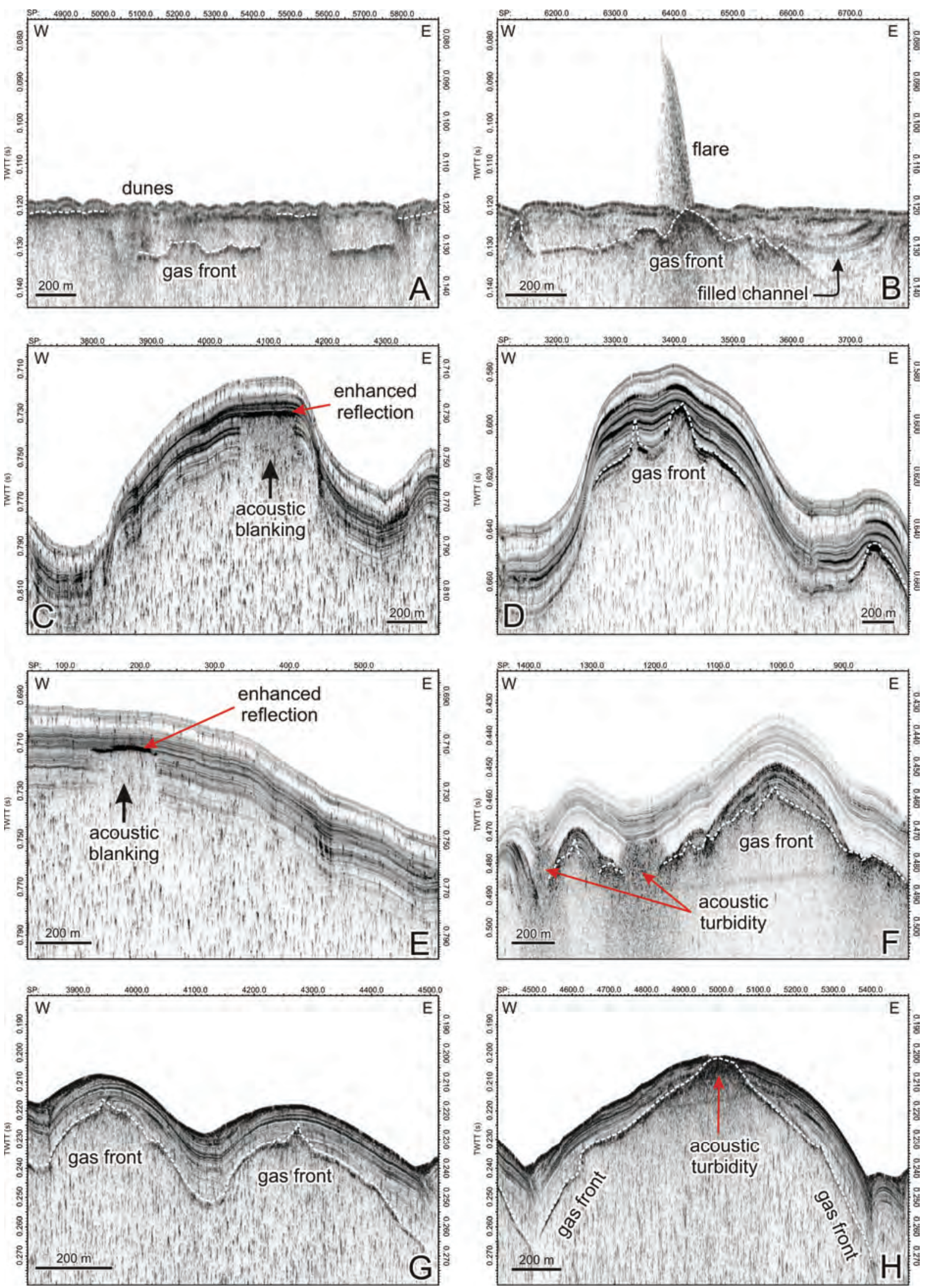

Figure 2.4. Different shallow gas signatures showing different behaviors on $5 \mathrm{kHz}$ pinger data (see Fig. 2.2.A. for location). 

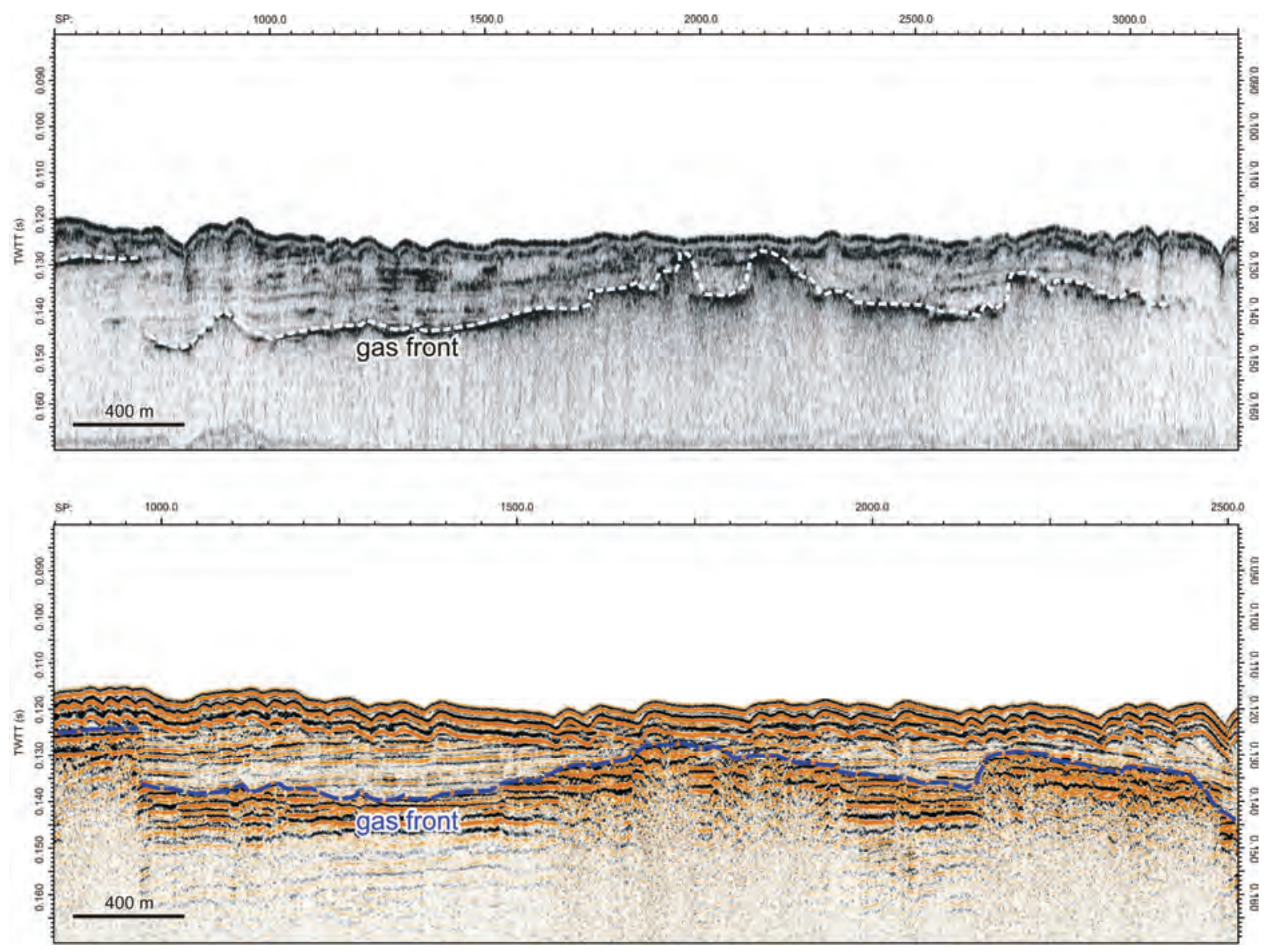

Figure 2.5. Comparison of "gas fronts" visible on $5 \mathrm{kHz}$ data and sparker data (see Fig. 2.2.A. for location).

already lead to a variety of shallow gas signatures on most types of high-resolution reflection seismic data (Figs. 2.4.-2.9.) (Judd and Hovland, 2007). The most common types of seismic disturbances related to gas-bearing sediments are "enhanced reflections" and "acoustic turbidity", both often in combination with "acoustic blanking" (Fig. 2.4.). "Enhanced reflections" on high-resolution reflection data are the analogues of "bright spots" on lowfrequency industrial data (Figs. 2.4.C. and 2.4.E.). They are characterized by anomalously high amplitude and are interpreted to be caused by the accumulation of (minor amounts of) free gas below a certain horizon. This gas accumulation causes a negative impedance contrast across that horizon, and the subsequent large-amplitude, phase reversed reflection on seismic data. "Acoustic turbidity" shows up on seismic data as a dark smear that sometimes cross-cuts the normal stratigraphy and completely masks all reflections below (Fig. 2.4.). "Acoustic turbidity" results from the attenuation (absorption and scattering) of the acoustic energy by the presence of gas bubbles within the sediment. The term "gas front" is often used for the top of the "acoustic turbidity" and associated gas features and is therefore interpreted as the upper limit of the free gas zone within the sediment (Fig. 2.4.). This interpretation is clearly supported by Fig. 2.4.B., on which the gas front can be seen to dome up to the seafloor and where a "flare", a hydroacoustic water-column anomaly caused by rising bubbles, is observed on the $5 \mathrm{kHz}$ data. Since higher frequencies are more strongly attenuated, the $5 \mathrm{kHz}$ pinger data provides the most valuable information about the depth variations of the shallow gas present in the sediments (Figs. 2.4.-2.6. and 2.9.). Comparison between the $5 \mathrm{kHz}$ data and sparker data (lower frequency) over a same area confirms that even if both types of seismic data clearly portray the gas front and its lateral depth variations, the 5 $\mathrm{kHz}$ data provide a higher-resolution image of the subsurface (Fig. 2.5.). The later is of course 


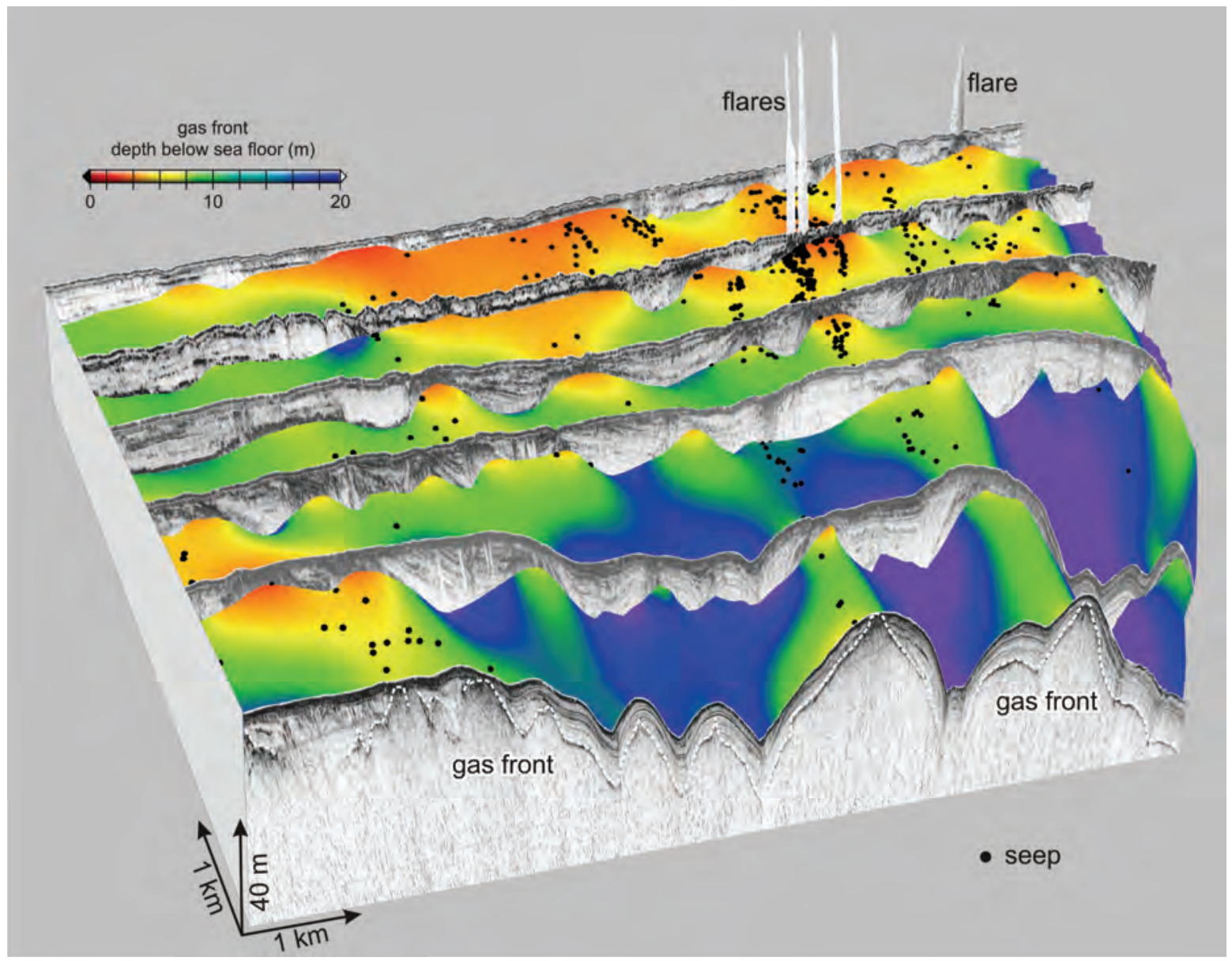

Figure 2.6. 3D view showing the depth variation of the gas front as a depth map overlain by an isopach map (depth of the gas front below the seafloor) together with the used $5 \mathrm{kHz}$ seismic profiles (see Fig. 2.2.A. for location). Gas seeps were mainly detected where the gas front approaches the seafloor within a couple of meters.

expected from a higher-frequency source. On the $5 \mathrm{kHz}$ data, the gas front shows up as a single, strong reflection, whereas on the sparker data the gas front rather appears as a combination of enhanced reflections. The comparison also shows that the sparker data only provide very little extra information of the deeper subsurface, less than would be expected from its lower frequency. The quality of these sparker data suffered significantly from a combination of several acquisition parameters (e.g. high vessel speed, engine noise, etc). The free gas within the sediments strongly attenuates the acoustic signal for both sources. Acoustic attenuation is largest when the acoustic frequency matches the resonant frequency of the bubbles, which stands in relation to the bubble size. The data suggest that a wide range of bubbles sizes occurs within the sediments imaged by the two seismic sources. However, the observation depth of the gas front is very similar for both methods. Both datasets show the presence of distinct "gas fronts", laterally strongly varying in depth and locally doming up towards the seafloor. The areas of "gas-front" updoming coincide with seep locations as observed by hydro-acoustics. By combining the gas front surface from the 5 $\mathrm{kHz}$ data with the seafloor surface, a "depth-togas-front" map was produced, which illustrates the strong "gas front-versus-seep" relationship that was observed on the seismic profiles (Fig. 2.6.). The majority of the seeps occur where the gas front approaches the seafloor within a couple of meters (Fig. 2.6.). The behavior or the depth variations of the "gas fronts" seem erratic at first, but a closer examination shows that "gas fronts" tend to dome up towards the seafloor at morphologic highs. Furthermore, "gas fronts" have the tendency to stay below the 
sedimentary infill of incised channels and only come up to the seafloor at the margins of these filled paleo-channels (Fig. 2.4.B.). Naudts et al. (2006) (CHAPTER 3) integrated the geophysical seismic data with multibeam data and coring information. Their results showed that the distribution and migration of gas near the seafloor in the Dnepr paleo-delta is predominantly controlled by stratigraphic and sedimentary factors, and not by faults as might be expected. In the Dnepr paleo-delta, alongstrata and across-strata variations in grain-size distributions and consequent changes in permeability seem to be the main controlling factors on shallow gas migration and accumulation outside the gas-hydrate stability zone (GHSZ).

\subsection{Gas hydrates}

Shallow gas within the sediments does not only occur as free gas (bubbles) or in dissolved form in sediment pore waters. It can also be trapped in crystalline, ice-like compounds composed of water and gas. These compounds are gas hydrates which are only stable at specific high-pressure and low-temperature conditions. In the marine environment, these conditions can generally be found at water depths of over 300$500 \mathrm{~m}$, depending on bottom-water temperatures and gas composition. The GHSZ is also limited to a certain depth below the seafloor because of the geothermally-induced rise in subsurface temperature with depth. Besides the P-T conditions, also the amount of available gas and water in the pore spaces needs to be high enough to sustain gas-hydrate growth and to keep hydrates stable. Marine gas hydrates have attracted massive attention from scientists and decision makers over the last decades, because they represent a possible energy resource as well as a geohazard. When P$T$ conditions change, gas hydrates can become unstable and dissociate. This can lead to sediment destabilization, submarine landsliding and possibly the generation of tsunamis. The dissociation of methane hydrates involves the release of large amounts of methane, which is a very strong greenhouse gas. If this methane would reach the atmosphere, it would strongly affect global climate.

In the northwestern Black Sea, methane gas hydrates are theoretically stable only below water depths of $-725 \mathrm{~m}$ due to the relatively high bottom-water temperatures of $8.9^{\circ} \mathrm{C}$. Hydrate stability calculation was done based on presumed average open-ocean pore-water salinity in the sedimentary column of $35 \mathrm{ppt}$ (Naudts et al., 2006). During the CRIMEA expeditions no gas hydrates were sampled by sediment coring in the Dnepr paleo-delta. However, based on seismic reflection profiling the presence of gas hydrates in the subsurface can be inferred geophysically from anomalous reflections. These reflections mimic the seafloor topography and are therefore referred to as bottom-simulating reflections (BSRs). The subsurface depth of the BSRs often corresponds to the lower P-T controlled boundary of the GHSZ, and is usually referred to as the base of the gas-hydrate stability zone (BGHSZ). Since BSRs mimic the seafloor, they often crosscut the reflections of the normal subhorizontal stratigraphy, making BSRs easy to identify. BSRs occur typically above high-amplitude reflections with a reverse negative phase polarity and underlie low-amplitude blanked reflections. Generally, it is assumed that the seismic signatures of BSRs are the result of relatively dense hydrate-bearing layers with high acoustic velocity overlying gassy sediments with low acoustic velocity. Deep drilling through BSRs have shown that BSRs can occur without the presence of hydrates in the subsurface and vice versa (Judd and Hovland, 2007).

Our GI-gun data also exhibit a BSR-like event, which is located at the calculated sub-bottom depth of the BGHSZ (Figs. 2.7.-2.8.). This BSR displays a number of characteristics of a typical BSR (i.e. low amplitudes above, enhanced reflections below, cross-cutting the stratigraphy, reverse polarity), but instead of appearing as a distinct, single reflection, the BSR on our data is expressed as a transition from high-amplitude (gas-enhanced) reflections below and lowamplitude (blanked) reflections above (Figs. 2.7.2.8.). Such seismic response is attributed to the relatively high frequency of the seismic signal and to the acquisition lay-out with relatively short offsets (Naudts et al., 2006). 


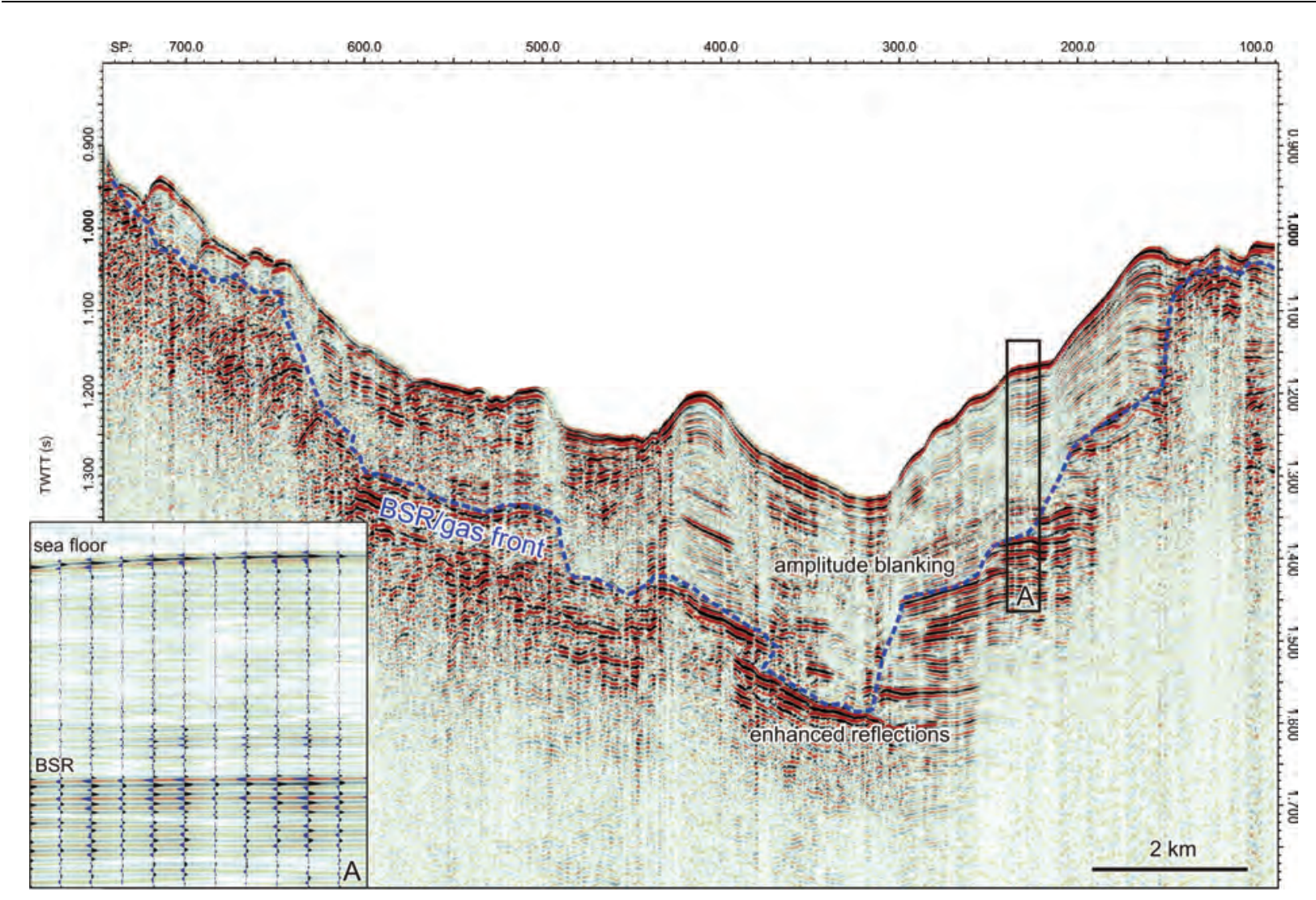

Figure 2.7. GI-gun reflection profile showing a BSR/gas front in the GHSZ. Inset A shows the inverse polarity of the BSR.

Seismic velocity analyses conducted within the CRIMEA project confirmed that the highamplitude reflections correspond to low-velocity gas-bearing horizons. Seismic inversion revealed that there is $38 \pm 10 \%$ hydrate in the pore space at BSR depth, where the porosity is $57 \%$ (Zillmer et al. 2005). Since the high-amplitude reflections below the BSR are caused by sedimentary strata containing free gas, we can also interpret the BSR as a gas front (Figs. 2.7.-2.8.). Where the BSR approaches the seafloor, close to $-725 \mathrm{~m}$ water depth, gas bubbles were detected in the water column (Fig. 2.8.), similarly to what was observed for the gas front outside of the GHSZ (Figs. 2.4. and 2.6.). It is important to realize that the physical processes controlling the depth of the free gas inside and outside the GHSZ are completely different, i.e. gas hydrates versus grain-size distribution. Nevertheless, sometimes it is hard to distinguish the transition from a "hydrate-controlled gas front" to a "grain-sizecontrolled gas front" (Fig. 2.8.) without having information about the extent of the GHSZ. In any case, our data clearly suggest that for the
Dnepr paleo-delta, gas hydrates present in the sediments are a major factor controlling shallow gas migration and accumulation within the GHSZ.

\subsection{Gas seeps}

Gas seeps are locations where gas bubbles escape from the seafloor in the overlying water column. They are the ultimate prove, in addition to the geophysical detection of shallow gas, that gas is present in the subsurface. The detection and localization of seeps is generally performed by means of echosounders, which detect gas bubbles in the water column due to the contrast in acoustic impedance between water and free gas in the bubbles (Figs. 2.2.B. and 2.3.). Seeps often have a distinct geomorphologic expression (e.g. pockmarks, mud volcanoes), which means that they can also easily be detected on highresolution reflection seismic data, on single- 


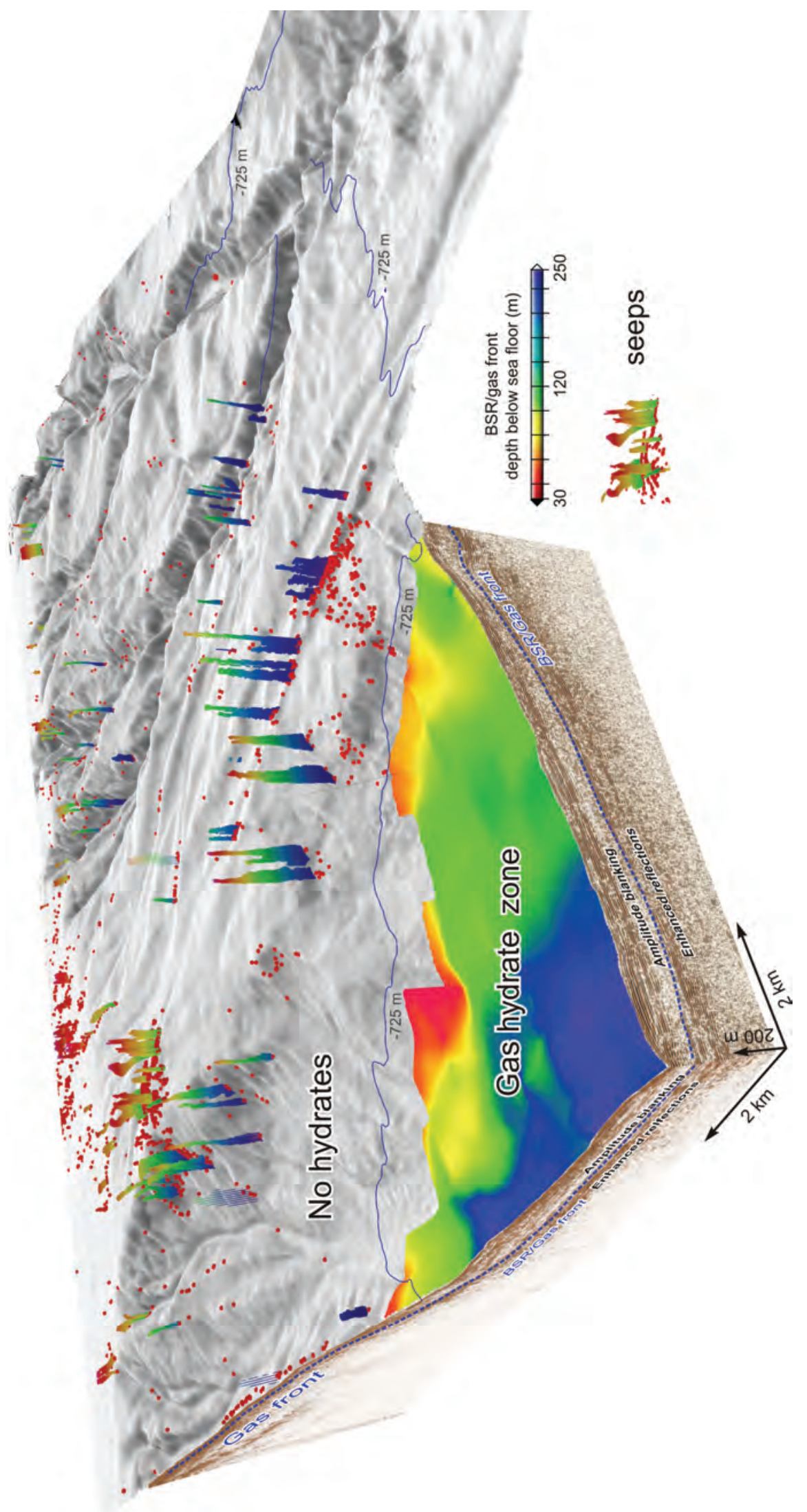

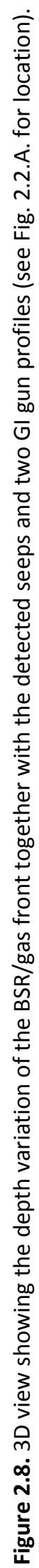


beam and multibeam echosounding data and on side-scan sonar recordings. The delineation of seep sites on the seafloor often arises from the detection of anomalously high acoustic backscatter on side-scan sonar or multibeam echosounder recordings. High-acoustic backscatter can be caused by abrupt changes in seafloor relief or by the enhanced acoustic impedance or roughness contrast between certain regions of the seafloor and their surroundings. At methane seeps, this contrast is primarily caused by the presence of methanederived authigenic carbonates (MDACs), chemosynthetic "cold seep" communities (e.g. clams, tube worms), gas bubbles or gas hydrates in the sediment. The variety and the uniqueness of these seep-related features at the seafloor made seep research to be a stand-alone (academic) research topic (Judd and Hovland, 2007). Recently, several studies have addressed the question of how gas seeps -methane seeps in particular- contribute to atmospheric methane concentrations and to the composition of the world ocean, and how they could affect global warming and the carbon cycle.
During the CRIMEA project, almost 3000 active bubble-releasing seeps were hydroacoustically detected within an area of $1540 \mathrm{~km}^{2}$ in the Dnepr paleo-delta (Figs. 2.2.B. and 2.3.) (Naudts et al., 2006). The distribution of these seeps is not random, but the seeps are concentrated in specific locations. Most remarkable is the almost complete absence of seeps in the GHSZ. As much as $95.5 \%$ of the detected seeps have a depth limit that coincides with the phase boundary of pure methane hydrate at $-725 \mathrm{~m}$ water depth (Fig. 2.8.). This suggests that gas hydrates not only control the distribution of subsurface gas, but also act as an effective seal and sink for methane, which prevents upward migration of methane gas and its release into the water column. Elsewhere, seeps generally occur in association with e.g. pockmarks on the continental shelf, along crests of sedimentary ridges, at bottoms, flanks and margins of canyons and associated with submarine landslides on the continental slope (Figs. 2.8.-2.9.) (Naudts et al., 2006). At all these sites, outside of the GHSZ, stratigraphy and sediment properties are the main factors

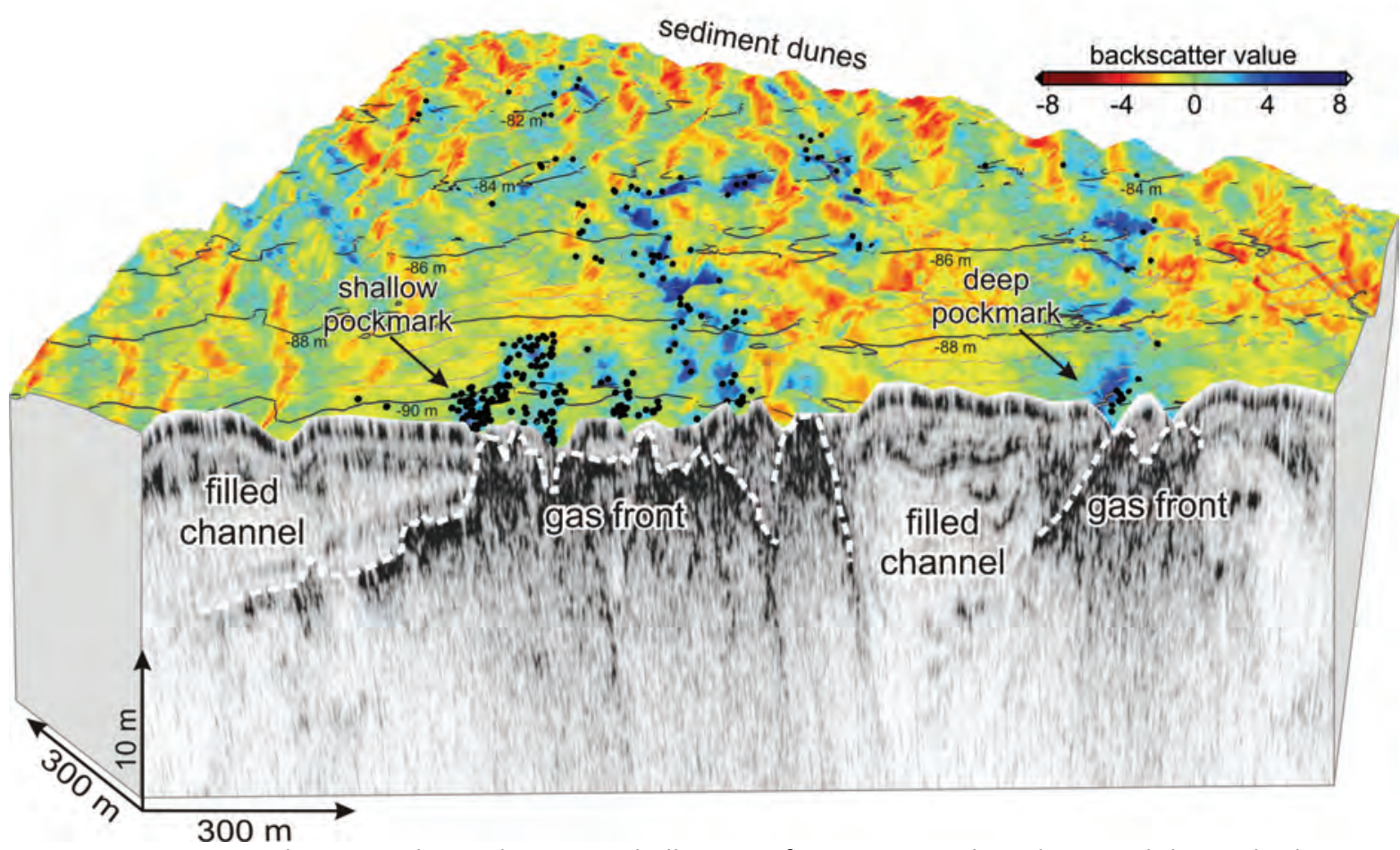

Figure 2.9. 3D view showing relation between shallow gas features on $5 \mathrm{kHz}$ data, multibeam bathymetry overlain by color-coded multibeam backscatter data and single-beam seep locations (see Fig. 2.2.A. for location). 
controlling the distribution of shallow gas and gas seeps, resulting in focused fluid flow and gas seepage in association with well-defined seafloor morphologies.

The highest abundance of seeps in the Dnepr paleo-delta was detected on the continental shelf in water depths ranging from $-72 m$ to -156 $\mathrm{m}$, where they commonly occur in association with up to $3 \mathrm{~m}$ deep, elongated, large (up to 100 $\mathrm{m}$ wide and $500 \mathrm{~m}$ long) pockmarks. Sedimentfilled channels control the depth of the gas front, which is only able to dome up at the edges of these filled channels. This is also where seeps occur (Fig. 2.9.). For the shelf region, these sediment-filled channels thus appear to be an important controlling factor on shallow-gas migration and gas-seep distribution. However, the multibeam backscatter data indicates an additional factor controlling shallow gas migration and seep distribution on the shelf of the Dnepr paleo-delta. The data show that seeps and a very shallow gas front are associated with pockmarks and with anomalously-high acoustic multibeam backscatter (Fig. 2.9.). Strikingly, the seeps do not occur at maximum highbackscatter values or in the deepest pockmarks, but they seem to occur preferentially in the surrounding medium- to high-backscatter areas, often in shallow pockmarks. Naudts et al. (2008) (CHAPTER 4) examined the cause of these backscatter anomalies and their relation with gas seepage by integrating the multibeam backscatter data with $5 \mathrm{kHz}$ pinger, multibeam bathymetry, hydro-acoustic seep detection, visual observations, sediment and pore-water data. This revealed that the backscatter anomalies are caused by the presence of methane-derived authigenic carbonates (MDACs) in the seafloor sediments, and it allowed to rule out alternative explanations, such as irregular pockmark morphology, grainsize distribution or subsurface gas bubbles (Naudts et al., 2008). The methane-derived carbonates are the result of the anaerobic oxidation of methane (AOM) by a consortium of sulfate-reducing bacteria and methane-oxidizing archaea, which utilize the methane dissolved in the sediment pore water and the sulfate available in the sea water. AOM results in the formation of sulfide and bicarbonate, giving way to sulfide-oxidizing bacterial mats at the seafloor and MDAC formation near the seafloor (Judd and Hovland, 2007). The absence of active seeps in areas with the highest backscatter values was explained as a result of longtime AOM-induced carbonate formation that leads to (self-)sealing of fluid pathways by carbonate clogging, followed by a relocation of the fluid/gas pathways around the cemented, impermeable areas. For the shelf of the Dnepr paleo-delta, MDAC formation controls, on a (sub-)meter scale, gas migration in the very shallow subsurface and the subsequent seep distribution (Naudts et al., 2008).

\subsection{Concluding remarks}

The integration of different geo- and hydroacoustic datasets allowed us to determine the presence and distribution of shallow gas, gas hydrates in the subsurface and gas seeps at the seafloor in the Dnepr paleo-delta, northwestern Black Sea. Furthermore, integration of the geoand hydro-acoustic datasets with non-acoustic data, such as visual observations and sediment cores, enabled us to identify the main controls on shallow-gas migration and gas-seep distribution in our study area. These controls comprise the presence of gas hydrates, continental slope morphology, stratigraphy and sediment properties (e.g. grain size), the presence of shelf-incised channels and the precipitation of methane-derived authigenic carbonates, each operating in different subenvironments and at a different spatial scale.

\section{Suggested reading}

The "bible" of shallow gas, gas hydrates and gas seeps is the textbook "Seabed fluid flow: the impact on geology, biology and the marine environment" by Judd and Hovland (Cambridge University Press, 2007). More detailed information about the data and results presented here can be found in "Geological and morphological setting of 2778 methane seeps in the Dnepr paleo-delta, northwestern Black Sea" by Naudts et al. (Marine Geology, 2006) and "Anomalous sea-floor backscatter patterns in methane venting areas, Dnepr paleo-delta, NW 
Black Sea" by Naudts et al. (Marine Geology, 2008).

\section{Acknowledgements}

We thank the captain and the crew of the $58^{\text {th }}$ and $60^{\text {th }}$ cruise of RV Professor Vodyanitskiy for their hard work and their hospitality and L-3 communications ELAC Nautik for their superior and fast support. This study was carried out in the framework of the CRIMEA project (http://www.CRIMEA-info.org) (EC project EVK2-CT-2002-00162). We also thank the SONIC Team for the pleasant collaboration and the collection of the pinger and side-scan sonar data. SMT (Kingdom Suite) and IVS (Fledermaus) are acknowledged for the academic licenses. Finally, we thank Gabor Tari and Michal
Nemcok, the guest editors of this special issue, for the invitation to publish this paper in TLE.

\section{Additional information}

Lieven Naudts processed and interpreted the datasets, wrote the manuscript and made all figures. Lieven Naudts also assisted with the data acquisition during the 12 weeks of expedition on RV Vodyanitskiy in 2003 and 2004. Co-authors helped by reviewing the manuscript and/or by providing the datasets. For the processing of the multibeam data assistance was given by Jens Greinert. For processing of the seismic data assistance was given by Peter Staelens. 